\title{
PENGARUH KADAR FLY ASH TERHADAP KUAT TEKAN PADAHIGH VOLUME FLY ASH- SELFCOMPACTING CONCRETE (HVFA-SCC) BENDA UJI D 15 CM X 30 CM USIA 28 HARI.
}

\author{
Isnadia Nurul Fatimah[1], Agus Setiya Budi[ ${ }^{[2]}$, Senot Sangadji[3] \\ [2]Pengajar Program Studi Teknik Sipil Fakultas Teknik Universitas Sebelas Maret \\ [3] Pengajar Program Studi Teknik Sipil Fakultas Teknik Universitas Sebelas Maret \\ Jl. Ir. Sutami 36 A, Kentingan Surakarta 57126. Telp (0271)647069. Fax 662118 \\ Email : isnadia.nf@gmail.com
}

\begin{abstract}
In an effort to reduce global warming due to $\mathrm{CO}_{2}$ waste from cement production used fly ash as a cement substitution material. The silica plus alumina compounds will bind the residual compound of the cement bydration (calcium bydroxide, $\mathrm{Ca}(\mathrm{OH})$ 2) which has no binding ability, to be a new compound that have cementitious properties The reaction makes the concrete stronger and solid. Fly ash also has a ball bearing effect that enhances workability. In this research will be analyzed the effect of fly ash content on compressive strength of each content of High Volume Fly Ash Self Compacting Concrete (HVFA-SCC) Fly Ash as a cement substitute at High Volume Fly Ash Self Compacting Concrete (HVFA SCC) has proportion start form 50\%. Concrete testing was performed with sample diameter $15 \mathrm{~cm}$ $\times 30 \mathrm{~cm}$ at 28 days. In this study comparing 3 variations of fly ash content in HCFA-SCC concrete that is 50\%, 60\%, 70\% and normal concrete. The results show that with the increase of fly ash content, the compressive strength of concrete decreased at 28 days. The resulting compressive strength of 50\%, 60\%, 70\% and normal concrete is $60.58 \mathrm{MPa}, 45.86 \mathrm{MPa}, 38.21 \mathrm{MPa}, 62.47 \mathrm{MPa}$.
\end{abstract}

Keywords : :HVFA SCC, fly ash, compressive strength

\section{ABSTRAK}

Dalam upaya mengurangi efek global warming akibat limbah $\mathrm{CO}_{2}$ hasil pembakaran semen ditelitilah fly ash sebagai bahan subtitusi semen. Kandungan senyawa silika ditambah alumina akan mengikat senyawa sisa hasil hidrasi semen (kalsium hidroksida, $\mathrm{Ca}(\mathrm{OH})_{2}$ ) yang tidak mempunyai kemampuan mengikat, menjadi senyawa baru yang mempunyai sifat cementitious (mengikat) sehingga meningkatkan kekuatan beton yang dihasilkan. Fly ash juga memiliki sifat ball bearing effect yang meningkatkan workability. Pada penelitian ini akan dianalisis pengaruh kadar fly ash terhadap kuat tekan yang dihasilkan masing masing kadar High Volume Fly Ash Self Compacting Concrete (HVFA-SCC) Fly Ash sebagai subtitusi semen pada High Volume Fly Ash Self Compacting Concrete (HVFA SCC) memiliki kadar mulai dari 50\%. Pengujian beton dilakukan dengan sample diameter $15 \mathrm{~cm}$ x $30 \mathrm{~cm}$ pada 28 hari. Pada penelitian ini dibandingkan 3 variasi kadar fly ash yaitu 50\%,60\%,70\% dan beton normal. Hasil penelitian menunjukkan kuat tekan HVFA-SCC semakin besar kadar fly ash semakin rendah kuat tekan yang dihasilkan. Kuat tekan yang dihasilkan untuk kadar fly ash $50 \%, 60 \%, 70 \%$ dan beton normal adalah $60.58 \mathrm{MPa}, 45.86 \mathrm{MPa}, 38.21 \mathrm{MPa}, 62.47 \mathrm{MPa}$.

Kata Kunci $\quad$ : HVFA SCC, fly ash, kuat tekan

\section{PENDAHULUAN}

Self Compacting Concrete (SCC) memiliki tingkat kecairan (fluidity) tinggi sehingga mampu mengalir dan mencapai kepadatan tertingginya sendiri tanpa mengalami pemisahan air dengan semen dari adukan (bleeding) maupun pemisahan agregat dari adukan (segregasi). Penggunaan beton SCC ini dapat memberikan keuntungan ekonomi karena beberapa faktor diantaranya menekan jumlah tenaga kerja dan mengurangi kebisingan karena proses pemadatannya tidak memerlukan bantuan alat penggetar (vibrator) dari segi kualitas beton SCC dinilai memiliki durabilitas yang baik serta menghasilkan permukaan beton yang rata dan halus.

Jika produksi beton SCC meningkat akan berbanding lurus dengan banyaknya semen yang harus diproduksi. Menurut Kementrian Perindustrian Republik Indonesia memperkirakan total kapasitas produksi semen pada tahun 2017 akan mencapai 102 juta ton dengan emisi karbondioksida yang dihasilkan sebesar 0,77 ton $\mathrm{CO}_{2}$ per ton semen yang diproduksi. Angka tersebut sangat besar pengaruhnya dalam timbulnya efek rumah kaca (green house effect) yang memicu terjadinya pemanasan global (global warming) 


\section{DASAR TEORI}

Pemakaian fly ash akan menurunkan kekuatan awal beton, namun dengan masih berlangsungnya reaksi pozzolanic maka kekuatan beton akan meningkat dalam jangka waktu yang lama. Reaksi kimia yang terjadi pada beton normal yaitu hidrasi $\mathrm{C}_{3} \mathrm{~S}$ dan $\mathrm{C}_{2} \mathrm{~S}$ adalah sebagai berikut :

$\begin{aligned} 2\left(3 \mathrm{CaO} \cdot \mathrm{SiO}_{2}\right)+6 \mathrm{H}_{2} \mathrm{O} & \stackrel{\text { Cepat }}{\longrightarrow} 3 \mathrm{CaO} \cdot \mathrm{SiO}_{2} .3 \mathrm{H} 2 \mathrm{O}+3 \mathrm{Ca}(\mathrm{OH})_{2} \\ 2 \mathrm{C} 3 \mathrm{~S}+6 \mathrm{H} & \stackrel{\text { Cepat }}{\longrightarrow} \mathrm{C}-\mathrm{S}-\mathrm{H} \text { gel }+3 \mathrm{CH} \\ 2\left(2 \mathrm{CaO} \cdot \mathrm{SiO}_{2}\right)+4 \mathrm{H}_{2} \mathrm{O} & \stackrel{\text { cepat }}{\longrightarrow} 3 \mathrm{CaO} \cdot \mathrm{SiO})_{2} \cdot 3 \mathrm{H} 2 \mathrm{O}+\mathrm{Ca}(\mathrm{OH})_{2} \\ 2 \mathrm{C}_{2} \mathrm{~S}+4 \mathrm{H} & \stackrel{\text { Cepat }}{\longrightarrow} \mathrm{C}-\mathrm{S}-\mathrm{H} \text { gel }+\mathrm{CH}\end{aligned}$

$\mathrm{Ca}(\mathrm{OH})_{2}$ sendiri adalah produk hidrasi reaksi dari semen dengan air yang memiliki sifat rapuh dan larut di dalam air. Kalsium hidroksida yang dihasilkan akan membuat sifat basa kuat $(\mathrm{pH}=12,5)$. Hal ini menyebabkan beton sensitif terhadap asam (Nugraha, 2007). Kalsium hidroksida dalam beton mudah sekali bereaksi dengan asam membentuk garam yang berdampak pada pengeroposan beton. Fly ash mengandung silika atau silika alumina yang memiliki sedikit atau tidak ada sifat semen tetapi apabila dalam bentuk butiran yang halus dan kondisi lembab, bahan ini dapat bereaksi secara kimia dengan $\mathrm{Ca}(\mathrm{OH})_{2}$ membentuk senyawa bersifat cementitious. Reaksi antara silika dengan kapur berlangsung sangat lambat, sehingga diperlukan waktu umur yang cukup lama untuk mencapai hasil kuat tekan yang optimal. Reaksi kimia $\mathrm{Ca}(\mathrm{OH})_{2}$ dengan $\mathrm{SiO}_{2}$ adalah sebagai berikut :

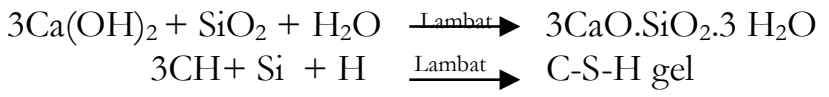

Dengan mencampurkan bahan pozolan pada jumlah yang sesuai dengan semen, unsur aktif $\mathrm{SiO}_{2}$ akan bereaksi secara sekunder dengan $\mathrm{Ca}(\mathrm{OH})_{2}$ untuk menghasilkan kalsium hidrosilikat. Menurut Mochamad Solikin(2011) pemakaian fly ash sebagai pengganti sebagian semen berguna terutama untuk meningkatkan durabilitas beton, karena kandungan silika $\left(\mathrm{SiO}_{2}\right)$ di dalam fly ash yang tinggi akan mengikat $\mathrm{Ca}(\mathrm{OH})_{2}$ untuk menghasilkan CSH (Calcium Silicat Hydarate), senyawa utama yang membangun kekuatan beton. Terlihat bahwa fly ash sebagai filler yang berfungsi mengisi ronggarongga kapiler (capillary porous) pada beton dan bereaksi dengan kapur bebas yaitu $\mathrm{Ca}(\mathrm{OH})_{2}$ membentuk CSH gel yang menyebabkan beton akan lebih padat, lebih kuat serta lebih kedap dan memiliki performa yang tinggi

\section{METODE PENELITIAN}

\section{Bahan dan Proporsi Campuran}

Bahan bahan yang digunakan untuk membuat campuran HVFA SCC antara lain :

1. Powder

a. Semen : semen yang digunakan adalah Ordinary Portland Cement Indocement.

b. Fly ash : fly ash yang digunakan adalah fly ash tipe F hasil dari PLTU Paiton. Fly ash digunakan sebagai subtitusi semen sebesar 50\%-70\%

2. Agregat kasar

Volume agregat kasar sebesar 50\% dari total volume beton. Ukuran butir maksimum untuk HVFA SCC adalah $16 \mathrm{~mm}$. Ukuran butir maksimum untuk beton normal adalah $35 \mathrm{~mm}$ Specific grafity sebesar 2,630 t/ $\mathrm{m}^{3}$

3. Agregat halus

Volume agregat halus sebesar 50\% dari total volume beton. Ukuran butir maksimum 0,125 mm. Specific grafity sebesar $2,560 \mathrm{t} / \mathrm{m}^{3}$

4. Air

FAS yang digunakan untuk HVFA SCC adalah sebesar 0,27 dan untuk beton normal 0,3

5. Bahan campur (admixture)

Bahan campur (admixture) yang digunakan adalah superplasticizer dengan merk Sika Viscocrete-10. 


\section{Rumus yang Digunakan}

$\sigma=\frac{F}{A}$

dengan :

$\sigma \quad=$ tegangan beton benda uji silinder $(\mathrm{MPa})$

$\mathrm{F} \quad=$ gaya desak maksimum $(\mathrm{N})$

A $\quad=$ luas permukaan benda uji silinder $\left(\mathrm{mm}^{2}\right)$

$\varepsilon=\frac{\Delta l}{l_{0}}$

dengan :

$\varepsilon \quad=$ regangan beton benda uji silinder

$\Delta \mathrm{l} \quad=$ selisih panjang awal dan akhir benda uji $(\mathrm{mm})$

$1_{0} \quad=$ panjang awal benda uji $(\mathrm{mm})$

Tabel 1. Proporsi Campuran HVFA SCC setiap $1 \mathrm{~m}^{3}$

\begin{tabular}{cccccccc}
\hline Kode & Kadar Fly Ash & Semen & Fly Ash & Fine Agg & Coarse Agg & Air & Superplacticizer \\
\hline HVFA.28.50 & $50 \%$ & 250 & 250 & 865,73 & 889,40 & 135 & 10 \\
\hline HVFA.28.60 & $60 \%$ & 200 & 300 & 863,19 & 886,79 & 135 & 10 \\
\hline HVFA.28.70 & $70 \%$ & 150 & 350 & 860,65 & 884,18 & 135 & 10 \\
\hline NC.28 & - & 500 & - & 687,38 & 1059,26 & 150 & 5
\end{tabular}

Pembuatan rancang campur menggunakan standar SNI-03-2384-2004 untuk beton normal dan EFNARC 2002 untuk beton High Volume Fly Ash Self Compacting Concrete (HVFA SCC). Beton HVFA 50\% disamakan mutunya dengan beton normal, mutu menjadi variabel terikat yang digunakan pada penelitian ini.

\section{HASIL DAN PEMBAHASAN}

Pengujian Fresh Concrete

Pengujian beton segar dilakukan sesuai aturan EFNARC 2002 "Specification and Guidelines for Self - Compacting Concrete". Pengujian yang dilakukan berupa Flow Table Test, L-Box test, V-Funnel test.

Tabel 2 Hasil Pengujian Flow Table Test HVFA-SCC

\begin{tabular}{cccccc}
\hline \multirow{2}{*}{ Kode } & \multicolumn{3}{c}{ Diameter } & \multicolumn{2}{c}{ Waktu } \\
\cline { 2 - 6 } & $\begin{array}{c}\mathrm{d} 1 \\
(\mathrm{~mm})\end{array}$ & $\begin{array}{c}\mathrm{d} 2 \\
(\mathrm{~mm})\end{array}$ & $\begin{array}{c}\mathrm{d}_{\text {rata-rata }} \\
(\mathrm{mm})\end{array}$ & $\begin{array}{c}\mathrm{t}_{50} \\
(\mathrm{dt})\end{array}$ & $\begin{array}{c}\mathrm{t}_{\text {maks }} \\
(\mathrm{dt})\end{array}$ \\
\hline HVFA28.50 & 657 & 660 & 658.5 & 658.5 & 4.6 \\
\hline HVFA28.60 & 676 & 672 & 674.0 & 674.0 & 4.2 \\
\hline HVFA28.70 & 735 & 732 & 733.5 & 733.5 & 3.2
\end{tabular}

Pada pengujian Flow Table pada tiga variasi kadar HVFA SCC memenuhi standar persyaratan beton SCC EFNARC 2002 dimana disyaratkan diameter yang harus dicapai adalah $600 \mathrm{~mm}-700 \mathrm{~mm}$ dalam waktu $2-5$ detik. Hasil ini menunjukkan beton HVFA SCC dengan penambahan kadar 50\%, 60\%, dan 70\% memiliki kemampuan filling ability yang baik. Beton ini dapat mengalir dan mengisi ruang celah pada tulangan dengan beratnya sendiri tanpa harus ada proses pemadatan.

Tabel 3 Hasil Pengujian L-Box HVFA-SCC

\begin{tabular}{cccccc}
\hline Kode & $\begin{array}{c}\mathrm{h}_{1} \\
(\mathrm{~mm})\end{array}$ & $\begin{array}{c}\mathrm{h}_{2} \\
(\mathrm{~mm})\end{array}$ & $\mathrm{h}_{2} / \mathrm{h}_{1}$ & $\begin{array}{c}\text { Syarat } \\
\left(\mathrm{h}_{2} / \mathrm{h}_{1}\right)\end{array}$ & Keterangan \\
\hline HVFA28.50 & 71 & 59 & 0.83 & $0,8-1,0$ & Memenuhi \\
\hline HVFA28.60 & 67 & 61 & 0.91 & $0,8-1,0$ & Memenuhi \\
\hline HVFA28.70 & 65 & 64 & 0.98 & $0,8-1,0$ & Memenuhi \\
\hline
\end{tabular}

Pada pengujian L-Box pada tiga variasi kada HVFA SCC memenuhi standar persyaratan beton SCC EFNARC 2002 dimana disyaratkan $h_{2} / h_{1}$ harus memiliki nilai $0,8-1,0$. Hasil ini menunjukkan beton HVFA SCC dengan 
penambahan kadar 50\%, 60\%, dan 70\% memiliki kemampuan passing ability yang baik. Beton ini dapat mengalir dan mengisi ruang celah pada tulangan dengan baik tanpa mengalami segregation ataupun blocking.

Tabel 4 Hasil Pengujian V-Funnel HVFA-SCC

\begin{tabular}{cccccc}
\hline \multirow{2}{*}{ Kode } & \multicolumn{3}{c}{ V-Funnel Test } & \multicolumn{3}{c}{ V-Funnel $T_{5 \text { minutes }}$} \\
\cline { 2 - 6 } & $\begin{array}{c}\mathrm{t} \\
(\mathrm{dt})\end{array}$ & $\begin{array}{c}\text { Syarat } \\
(\mathrm{t})\end{array}$ & Keterangan & $\begin{array}{c}\mathrm{t} \\
(\mathrm{dt})\end{array}$ & $\begin{array}{c}\Delta \mathrm{t} \\
(\mathrm{dt})\end{array}$ \\
\hline HVFA28.50 & 10.3 & $6-12 \mathrm{dt}$ & Memenuhi & 11.7 & 1.4 \\
\hline HVFA28.60 & 8.7 & $6-12 \mathrm{dt}$ & Memenuhi & 10.2 & 1.5 \\
\hline HVFA28.70 & 7.2 & $6-12 \mathrm{dt}$ & Memenuhi & 9.8 & 2.6 \\
\hline
\end{tabular}

Pada pengujian $V$-Funnel pada tiga variasi kada HVFA SCC memenuhi standar persyaratan beton SCC EFNARC 2002 dimana disyaratkan waktu yang harus ditempuh adalah $6-12$ detik. Dan pada pengujian $V$-Funnel $T_{5 \text { minutes }}$ dimana beton segar didiamkan selama 5 menit dan di tes kembali pada $V$-Funnel juga menunjukkan bahwa beton HVFA SCC dengan kadar $50 \%, 60 \%$, dan 70\% ini memenuhi standar EFNARC 2002 . Hasil ini menunjukkan beton HVFA SCC dengan penambahan kadar 50\%, 60\%, dan 70\% memiliki segregation resistance yang baik. Beton ini mempu tetap homogen saat proses pengiriman dan pengecoran.

\section{Hasil Pengujian Kuat Tekan}

Pada saat benda uji berumur 28 hari dilakukan pengujian kuat desak beton menggunakan Universal Testing Machine (UTM) untuk benda uji HVFA-SCC 70\%,60\% dan menggunakan Compresion Testing Machine (CTM) untuk benda uji HVFA-SCC 50\%, normal untuk mendapatkan beban maksimum (Pmaks)

Tabel 5. Hasil Kuat Tekan Beton HVFA SCC dan Beton Normal

\begin{tabular}{ccccc}
\hline Kode & Kadar & Luas $\left(\mathrm{mm}^{2}\right)$ & Umur (hari) & Kuat Tekan (MPa) \\
\hline HVFA.28.50 & $50 \%$ & 17750,12 & 28 & 60,58 \\
\hline HVFA. 28.60 & $60 \%$ & 17632,25 & 28 & 45,86 \\
\hline HVFA. 28.70 & $70 \%$ & 17750,65 & 28 & 38,21 \\
\hline NC. 28 & - & 17750,65 & 28 & 62,47 \\
\hline
\end{tabular}

Berdasarkan tabel hasil pengujian diatas didapat bahwa beton HVFA SCC dengan kadar 50\% memiliki kuat tekan paling tinggi yaitu 60,58 MPa, pada HVFA SCC 60\% kuat tekan yang dihasilkan 45,86 MPa dan pada HVFA SCC $70 \%$ kuat tekan yang dihasilkan 38,21 MPa. Sebagai pembanding pada beton normal dihasilkan kuat tekan 62,47 MPa dari hasil tersebut dapat dilihat penambahan persentase fly ash pada sampel beton normal maupun HVFA-SCC berpengaruh pada kekuatan beton. Beton dengan kadar fly ash semakin tinggi maka kuat tekan beton semakin menurun. Hal tersebut karena fly ash pada adukan yang dibuat berfungsi sebagai subtituen semen yang berarti prosentase semen sebagai bahan pengikat utama menjadi turun. Selain itu pada umur 28 hari, reaksi antara fly ash dengan hasil sekunder reaksi hidrasi semenyaitu $\mathrm{Ca}(\mathrm{OH})_{2}$ untuk membentuk C-S-H belum terjadi secara optimal sehingga membuat kuat tekan beton belum maksimal.

Fly ash memiliki dormant period yang lama dan bereaksi setelah $\mathrm{pH}$ 13.3. Kondisi ini dibutuhkan untuk memecah glass phase, sehingga fly ash tidak bisa berkontribusi di early strength development.Reaksi hidrasi yang terjadi pada fly ash hanya berlangsung pada permukaan hingga ke ketebalan 0.3-0.4 $\mu \mathrm{m}$, sehingga di akhir reaksi volume phase fraction dari fly ashrelatif banyak dibandingkan semen. Strength evolution dari high volume fly ash concrete dipengaruhi oleh degree of reaction dari fly ash yang persamaan numerik terhadap fungsi waktu, disamping itu pozzolanic reaction dalam fly ash cement blends masih dapat diamati dalam jangka waktu yang lama.Evolusi dari kalsium hidroksida, chemically bound water dan capillary water di cement-fly ash blends bergantung kepada degree of bydration dari semen dan degree of reaction dari fly ash. 


\section{SIMPULAN}

Dari hasil pembahasan diatas dapat diambil beberapa kesimpulan sebagai berikut :

1. Dengan penambahan kadar fly ash 50\%, 60\% dan 70\% persyaratan beton segar Self Compacting Concrete tetap terpenuhi

2. Kuat tekan semakin menurun akibat bertambahnya kadar fly ash pada beton.

\section{REKOMENDASI}

a. Perlu penelitian lebih lanjut mengenai variasi umur beton HVFA-SCC pada umur 56 hari dan 90 hari, mengingat beton HVFA-SCC masih mengalami kenaikan kuat tekan yang cukup signifikan pada umur tersebut.

b. Dengan sample $15 \mathrm{~cm}$ x $30 \mathrm{~cm}$ mutu beton yang dibuat jangan lebih dari 50 Mpa karena maximum load yang dihasilkan pada mesin Universal testing Mechine hanya $1000 \mathrm{kN}$. Agar dihasilkan grafik tegangan regangan hingga post peak

\section{UCAPAN TERIMA KASIH}

Ucapan terima kasih penulis sampaikan kepada Bapak Agus Setiya Budi, S.T., M.T. dan Bapak Dr. Senot Sangadji S.T.,M.T. selaku pembimbing yang dengan penuh kesabaran telah memberi koreksi dan arahan sehingga menyempurnakan penyusunan. Rasa terima kasih penulis sampaikan khusus untuk tim Beton Sabar selaku tim kerja yang pantang menyerah.

\section{REFERENSI}

ACI Committee 116,.1990.“Cement and Concrete Terminology (ACI 116R-90)”, American Concrete Institute, Farmington Hills

Anonim. 2000. “SN1 03-6414-2002, "Pengertian dan Manfaat Fly Ash”. Badan Standarisasi Nasional, Jakarta.

Anonim. 2000. "SN1 03-2834-2000, "Tata Cara Pembuatan Rencana Campuran Beton Normal". Badan Standarisasi Nasional, Jakarta.

Anonim, PBI 1971. 1971. "Peraturan Beton Bertulang”.Yayasan Lembaga Penyelidikan Masalah Bangunan. Bandung.. Anonim. 2000. "SNI 03-1974-1990, "Metode pengujian kuat tekan beton". Badan Standarisasi Nasional, Jakarta

ASTM C 618-93. 1991. "Standard Test Method for Fly Ash and Row or calcined Natural Pozzolan for Use as a mineral Admixture in Portland Cement Concrete", American Society for Testing of Concrete's

ASTM C 618-03, 2003.Standard Specification for Pozzoland and Raw or Calcined Natural Pozzolan for Use in Concrete. United States:Association of Standard Testing Materials

EFNARC.2002." Specification and Guidelines for Self-Compacting Concrete" 